\title{
Phytochemical, Antioxidant and Photo-Protective Activity Study of Bunga Kantan (Etlingera elatior) Essential Oil
}

\author{
Poh-Yen Khor ${ }^{*}$, Fatin Shuhada Na'im Mohamed, Ikrimah Ramli, Nur Fatihah Asyiqin Mohd Nor, \\ Siti Khatijah Che Mohd Razali, Jasreen Ariesha Zainuddin, Nur Sahira Mohd Jaafar \\ Pharmacy Department, Royal College of Medicine Perak, Universiti Kuala Lumpur, 3, Jalan Greentown, 30450, Ipoh, Perak, Malays ia.
}

\begin{tabular}{|c|c|}
\hline ARTICLE INFO & ABSTRACT \\
\hline Article history: & \multirow{10}{*}{$\begin{array}{l}\text { The three main objectives of this study were to evaluate the extracted essential oil in terms of total phenolic and } \\
\text { flavonoids contents, radical scavenging activity and sun protection factor. The antioxidant activity of the } \\
\text { essential oil was determined by using 2, 2-diphenyl-1-picrylhydrazyl (DPPH) radical scavenging activity while } \\
\text { the content of total phenol was determined by using Folin-Ciocalteu reagent. Aluminium chloride colorimetric } \\
\text { method was used for flavonoid content determination while photo-protective potential was determined by using } \\
\text { Mansur's sun protection factor (SPF) value. The extracted essential oil was found to contain low levels of total } \\
\text { phenolic contents }(2.30 \pm 0.003 \mu \mathrm{g} / \mathrm{g} \text { as garlic acid equivalent) and total flavonoid contents }(254.99 \pm 0.64 \mu \mathrm{g} / \mathrm{g} \text { as } \\
\text { quercetin equivalent) respectively. DPPH free radical scavenging activity of the essential oil was } 40.73 \% \pm 1.32 \text { at } \\
200 \mu \mathrm{g} / \mathrm{ml} \text {. The Mansur's equation of sun protective factor showed that the essential oil possesses some sun } \\
\text { protective potentials. This study suggests that the essential oil from Etlingera elatior could be potentially used } \\
\text { as a new source of natural antioxidant and ingredient that can be incorporated into the sunscreen cosmetic } \\
\text { products. }\end{array}$} \\
\hline Received on: 02/04/2017 & \\
\hline /05/2017 & \\
\hline Available o & \\
\hline Key words: & \\
\hline Essential Oil, Bunga Kantan, & \\
\hline Etlingera elatior, & \\
\hline Antioxidant, Photo- & \\
\hline Protective Activity, & \\
\hline Phytochemical. & \\
\hline
\end{tabular}

\section{INTRODUCTION}

The essential oil is an odorous and volatile product that originates from plant species. These plant species usually produce characteristic aroma from different plant parts: leaves, stems, flowers and roots or rhizomes. Chemically, a single drop of the volatile oil is made up of more than 200 different chemical components, and most of these trace constituents are solely responsible for this characteristic flavour (Doughari, 2009).

Etlingera elatior (EE) or locally known as bunga kantan in Malaysia with its characteristic sweet fragrance has been widely cultivated especially as spices for curry. Bunga Kantan, which belongs to the Zingiberaceae family, is herbaceous perennial plant native to Sumatra and other parts of Indonesia. Besides the name bunga kantan, it is also called as

* Corresponding Author

Poh-Yen Khor, Pharmacy Department, Royal College of Medicine Perak, Universiti Kuala Lumpur, 3, Jalan Greentown, 30450, Ipoh, Perak, Malaysia.Email: pykhor @ unikl.edu.my 'torch ginger' or 'red ginger lily' in English and "kecombrang" or "honje" in Indonesian. The chemical constituents of the essential oil have been categorised into alcohol, aldehyde, ester, hydrocarbon, monoterpene derivative, sesquiterpene and its derivatives (Chan et al., 2010). Amongst these constituents, monoterpene hydrocarbon is present as major compounds (Doughari, 2009) while 2-undecanone was associated with insect repellent potential (Khalid and Azman, 2016). Previous studies on various crude extracts from the plant parts of $\mathrm{EE}$ have been associated with its pharmacological or medicinal uses; methanol and ethyl acetate extracts were found to be antimicrobial and antifungal agent (Lachumy et al., 2010) and ethyl acetate of the flower extract was found to have antioxidant activity as well as a wide range of phyto-constituents (Maimulyanti and Prihadi, 2015). Studies involving the comparison of the plant parts of $E E$ collected from different locations in Malaysia also revealed that the flowers exhibited promising anticancer activity, which is attributed to the presence of high amount of phenolic and flavonoid compounds (Ghasemzadeh et al., 2015). 
However, according to literature, there was only one study that had reported on the antioxidant properties from the $E E$ essential oil (Abdelwahab et al., 2010) while no exploration was done on the photo-protective activity. Exploring photo-protective activity from herbal plant resources has been gaining increasing attention in recent years. Rojas et al. (2016) reviewed essential oils and plant extracts from more than 40 types botanical sources showed that photo-protective activities of these plants were attributed to the secondary metabolites such as flavonoids, alkaloids, etc. Eleven medicinal plants from Sri Lanka were found to display high sun protection factors (SPF > 25) compared to wellknown medicinal plant, Aloe vera (Napagoda et al., 2016). Furthermore, studies on the use of natural antioxidants in sunscreens to provide supplementary photo protective action activity gave rise to the new possibilities for the treatment and prevention of UV-mediated diseases (Costa et al., 2015; Iman et al., 2015; Silva et al., 2014). Since the anti-oxidant properties were not fully studied and the photo-protective potential of the $E E$ essential oil were not explored, this research were carried out with three objectives; which are to evaluate, (i) the total phenolic and flavonoids contents, (ii)the radical scavenging activity and,(iii)the sun protection factor of the $E E$ essential oil.

\section{MATERIALS AND METHODS}

\section{Plant Materials}

The $E E$ flower and stem in this study were collected from a local market in Ipoh, Perak, Malaysia. Only mature $E E$ with flower at full bloom were choose for this study (Choon and Ding, 2016) and identification were performed at Biology Department, Universiti Pendidikan Sultan Idris, Malaysia. The plant materials were washed, chopped into small pieces and air-dried in a shady place at room temperature for 5 days to minimize the losses of antioxidant properties due to thermal degradation. The dried plant materials were then ground into fine powder at a total mass of 210 gram.

\section{Extraction of the Essential Oil}

The total of 210 gram fine $E E$ powder obtained was subjected to 5-6 hours of hydro-distillation using a simple distillation method (Siddique et al., 2012;Jaafar et al., 2007). The essential oil was isolated by extraction of the distillate with one liter of dichloromethane using a separating funnel for three times. The mixture of the distillate and dichloromethane was shaken for 5 minutes and allowed to stand over night. The organic layer was separated and concentrated by evaporation under pressure until a constant weight was gained. The weight of the extracted oil was calculated and kept in a sealed vial at $4^{\circ} \mathrm{C}$ for further analysis.

\section{Phytochemical Screening}

The extracted essential oil was subjected to preliminary phytochemical screening to determine the types of phytochemicals present in the essential oil (Prashant Tiwari et al., 2011).

\section{Determination of Total Phenolic Content}

Total phenolic content in the essential oil was measured using the Folin-Ciocalteu reagent method (Mohamed et al., 2013). Briefly, $200 \mu \mathrm{L}$ essential oil ( $5 \mathrm{mg}$ oil $/ \mathrm{ml}$ ethanol) was made up to $3 \mathrm{ml}$ with distilled water which was then mixed thoroughly with $0.5 \mathrm{ml}$ of Folin-Ciocalteu reagent. After mixing for one min, $2 \mathrm{ml}$ of $20 \%(\mathrm{w} / \mathrm{v})$ sodium carbonate was added and allowed to stand for one hour in the dark. The absorbance of the reaction mixtures was measured at $650 \mathrm{~nm}$ (Lamda 35, UV/Vis Spectrophotometer Perkin Elmer, 190-1100 nm), and the results were expressed as $\mu \mathrm{g}$ Gallic acid (GAE)/g of dry weight. Gallic acid concentrations ranging from 1 to $5 \mu \mathrm{g} / \mathrm{mL}$ were prepared and the standard calibration curve was obtained using a linear fit at $\mathrm{r} 2=0.9855$ (Figure 1).Triplicate measurement were made for each test sample. The result was expressed as gallic acid equivalent.

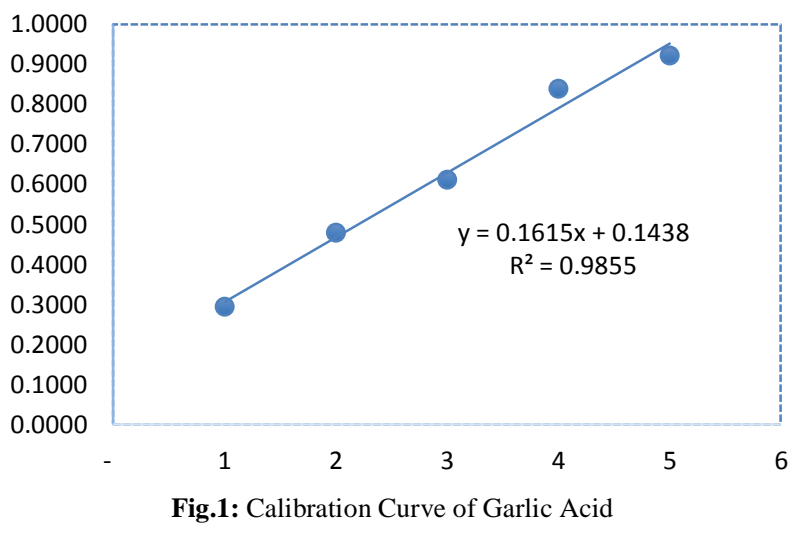

\section{Determination of Total Flavonoid Content}

Total flavonoid content was determined by using aluminium chloride method with quercetin as standard (Seow et al., 2016). Briefly, $1 \mathrm{~mL}$ of $2 \% \mathrm{w} / \mathrm{v}$ aluminium chloride was added to $200 \mu \mathrm{L}$ essential oil ( $5 \mathrm{mg}$ oil $/ \mathrm{ml}$ ethanol). After vortexing for 10 seconds, the mixture was incubated at room temperature for one hour. The absorbance of the solution was measured at $420 \mathrm{~nm}$. Quercetin concentrations ranging from 5 to $500 \mu \mathrm{g} / \mathrm{mL}$ were prepared and the standard calibration curve was obtained using a linear fit at $\mathrm{r} 2=0.9765$ (Figure2). Triplicate measurements were made for each test sample. The result was expressed as quercetin equivalent.

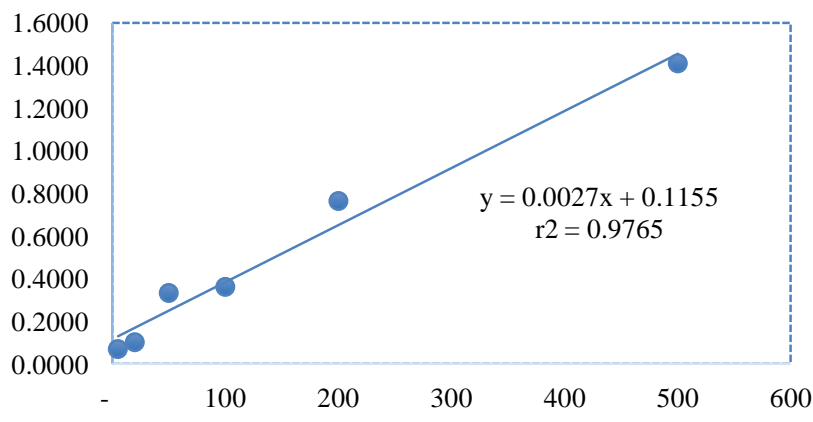

Fig 2: Calibration Curve of Quercetin. 


\section{Determination of Radical Scavenging Antioxidant Activity}

The radical scavenging anti-oxidant activity of the essential oil was determined by slightly modified DPPH radical scavenging assay (Mohamed et al., 2013). Briefly, a $0.1 \mathrm{mM}$ solution of 2, 2- diphenyl-1-picryl-hydrazyl (DPPH) in methanol was prepared and $1 \mathrm{ml}$ of this solution was added to $3 \mathrm{ml}$ of the essential oil at different concentrations $(20-500 \mu \mathrm{g} / \mathrm{ml})$. Gallic acid which was used as a positive control was prepared at different concentrations (20-200 $\mu \mathrm{g} / \mathrm{ml})$ and a calibration curve was plotted (Figure 3). Discolouration was measured at $517 \mathrm{~nm}$ after incubation for 30 minutes in the dark. Measurements were taken in triplicate. The capacity to scavenge the DPPH radical was calculated following $\%$ inhibition $=\left[\left(\mathrm{A}_{0}-\mathrm{A}_{\mathrm{A}}\right) /\left(\mathrm{A}_{0}\right)\right] \mathrm{x} 100$ where $\mathrm{A}_{0}$ is absorbance of blank sample and $\mathrm{A}_{\mathrm{A}}$ is absorbance of test sample.

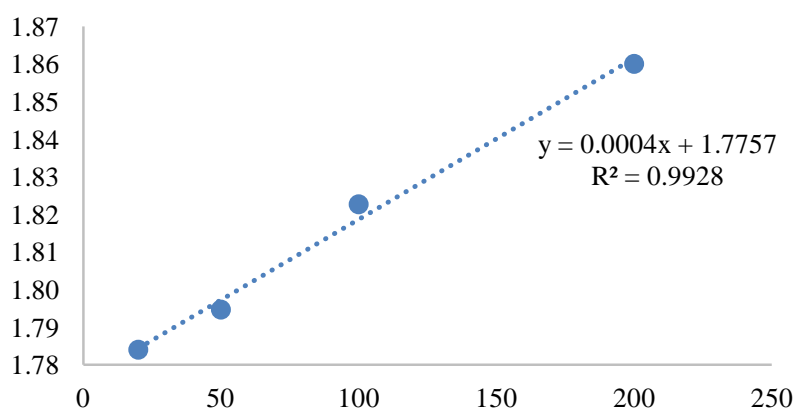

Fig 3: Calibration Curve of Garlic Acid in DPPH

\section{Determination of in-vitro Photo- Protective}

The photo-protective potential of the essential oil was indicated by the sun protection factor (SPF) following the Mansur's method (Kaur and Saraf, 2011). Briefly, 200 $\mathrm{g} / \mathrm{ml}$ essential oil was prepared. The absorbance of the essential oil was measured from $290-320 \mathrm{~nm}$, at $5 \mathrm{~nm}$ interval. Methanol was used as blank. The observed absorbance values at $5 \mathrm{~nm}$ intervals (290$320 \mathrm{~nm}$ ) were calculated by using the formula SPF spectrophotometric:

$$
\mathrm{SPF}=C F x \sum_{290}^{320} \mathrm{EE}(\lambda) \mathrm{xI}(\lambda) \mathrm{x} \operatorname{Abs}(\lambda)
$$

Where, $\mathrm{CF}=$ correction factor (10), $E E(\lambda)$ - erythemal effect spectrum; $I(\lambda)$ - solar intensity spectrum; Abs (ג) - absorbance of sunscreen product.

\section{Statistical Analysis}

All results were presented as the mean \pm standard deviation. Using Statistical Package for the Social Sciences (SPSS) version. 17, the analysis of variance, correlation and student's t-test were performed. The $p$ value $(P<0.05)$ was considered as statistically significant level.

\section{RESULT AND DISCUSSION}

The hydro-distillation of EE yielded $0.063 \%(w / w)$ of essential oil. The oil obtained was light yellowish with a strong, pleasant-smell. This result is in consistent with the previous study which reported that a typical sample of hydro-distillation yield from different plant parts ranged from $0.0021 \%-0.07 \%$ (Jaafar et al., 2007).

Compared with other organic solvent distillation, the yield reported in this study was comparatively low; this can be attributed to the availability of extractable components based on different solvent polarity (Maimulyanti and Prihadi, 2015). Although hydro-distillation in this study produced low yield, water as extraction solvent is considered the best choice because it follow the same manner as the traditional medicine is prepared.

The phytochemical results are shown in Table 1 . The screening results showed that the $E E$ possesses steroids, phenol, flavonoids and trace amount of amino acids. Till now, no data has ever been published on the phytochemical screening of the essential oil. In comparison with crude extracts (Maimulyanti and Prihadi, 2015), this study confirms the presence of alkaloids which had never been reported before. Alkaloids are nitrogenous compounds which function in the defence of plants against herbivores and pathogens. They are widely exploited for their antimicrobial and antibiotic activities (Prashant Tiwari et al., 2011). Thus the antimicrobial activity reported in the essential oil of $E E$ in previous studies could be partially contributed by the alkaloids.

Assessment of total phenolic and flavonoid contents of the essential oil are presented in Table 2. Phenolic and flavonoids contents were $2.30 \pm 0.003 \mu \mathrm{g} / \mathrm{g}$ and $254.99 \pm 0.64 \mu \mathrm{g} / \mathrm{g}$ respectively; both chemical components occur ubiquitously as natural colour pigments, which contribute to the attractive colour of the $E E$ flower.

It is a note worthy that the essential oil contains significantly higher flavonoid content than phenolic content $(\mathrm{P}<$ 0.005 )(Table 2). This result is similar in other plant species (Nurain et al., 2013); but contradicted with the $E E$ essential oil study reported earlier (Abdelwahab et al., 2010). Different results obtained could be due to the plant maturity, seasons and geographical locations of the different of plant materials collected (Çetinkaya et al., 2016).

The higher concentration of flavonoids as compared to phenolic content could be specifically attributed to the quercetin or quercetin derivative which is structurally matching to the quercetin standard used in this study. This explanation is also reasonable as quercetin is present in nearly $70 \%$ of all the plants (Doughari, 2009) and so this is the reason for the higher probability of its presence in the essential oil extracted from $E E$ in this study.

The radical scavenging effect of $E E$ is reported in Table 2. At the concentration of $200 \mu \mathrm{g} / \mathrm{g}$, the essential oil and gallic acid was determined as $40.73 \%$ and $94.86 \%$ respectively. This result indicated that gallic acid scavenging effects was significantly higher than the essential oil $(\mathrm{P}=0.00)$, and it was determined as concentration-dependent $(r=0.9806)$ (Figure 3$)$. The higher the concentration of the essential oil, the higher the level of inhibitory activity against the free radicals (Figure 4). 
Table 1: Phytochemical Screening Result.

Test

Detection of alkaloids

Wagner's test

Meyer's test

Hager's test

Detection of carbohydrates

Molisch's Test

Benedict's Test

Detection of glycosides

Legal's Test

Detection of phytosterols

Salkowski's Test

Detection of phenols

Ferric Chloride Test

Detection of flavonoids

Alkaline Reagent Test

Detection of proteins and amino acids

Xanthoproteic test

Table 2: Total Phenolic and Flavonoid Contents and Antioxidant Activity of the EE Essential Oil.

Description

Total phenolic

Total flavonoid

Essential oil Scavenging effect*

Garlic acid Scavenging effect*

*at $200 \mu \mathrm{g} / \mathrm{g}$

\begin{tabular}{cl} 
Concentration & Regression \\
\hline $2.30 \pm 0.003 \mu \mathrm{g} / \mathrm{g}$ & $\mathrm{y}=0.1615 \mathrm{x}+0.1438, \mathrm{R}^{2}=0.9855$ \\
$254.99 \pm 0.64 \mu \mathrm{g} / \mathrm{g}$ & $\mathrm{y}=0.0027 \mathrm{x}+0.1155, \mathrm{R}^{2}=0.9765$ \\
$40.73 \% \pm 1.32$ & $\mathrm{y}=0.0002 \mathrm{x}+0.6968, \mathrm{R}^{2}=0.9978$ \\
$94.86 \% \pm 0.61$ & $\mathrm{y}=0.0004 \mathrm{x}+1.7757, \mathrm{R}^{2}=0.9928$
\end{tabular}

Table 3: SPF value of Etlingera elatior essential oil.

\begin{tabular}{|c|c|c|c|c|c|c|c|}
\hline $\begin{array}{c}\text { Wavelength } \\
(\mathbf{n m})\end{array}$ & $\begin{array}{c}\mathbf{E E}(\lambda) \\
x \mathbf{I}(\lambda)\end{array}$ & $\begin{array}{l}\text { Abs. } \\
\left(\mathbf{A}_{1}\right)\end{array}$ & EExIxA & $\begin{array}{l}\text { Abs. } \\
\left(\mathbf{A}_{2}\right)\end{array}$ & EExIxA & $\begin{array}{l}\text { Abs. } \\
\left(\mathbf{A}_{3}\right)\end{array}$ & EExIxA \\
\hline 290 & 0.0150 & 0.441 & 0.007 & 0.44 & 0.007 & 0.442 & 0.007 \\
\hline 295 & 0.0817 & 0.396 & 0.032 & 0.396 & 0.032 & 0.398 & 0.033 \\
\hline 300 & 0.2874 & 0.381 & 0.109 & 0.381 & 0.109 & 0.381 & 0.109 \\
\hline 305 & 0.328 & 0.355 & 0.116 & 0.357 & 0.117 & 0.354 & 0.116 \\
\hline 310 & 0.186 & 0.331 & 0.062 & 0.330 & 0.062 & 0.331 & 0.062 \\
\hline 315 & 0.084 & 0.291 & 0.024 & 0.290 & 0.024 & 0.291 & 0.024 \\
\hline 320 & 0.018 & 0.254 & 0.005 & 0.252 & 0.005 & 0.252 & 0.005 \\
\hline
\end{tabular}

$\mathrm{SPF}=\sum \operatorname{EE}(\lambda) \mathrm{x}(\lambda) \times \mathrm{Ax} 10$ (correction factor)

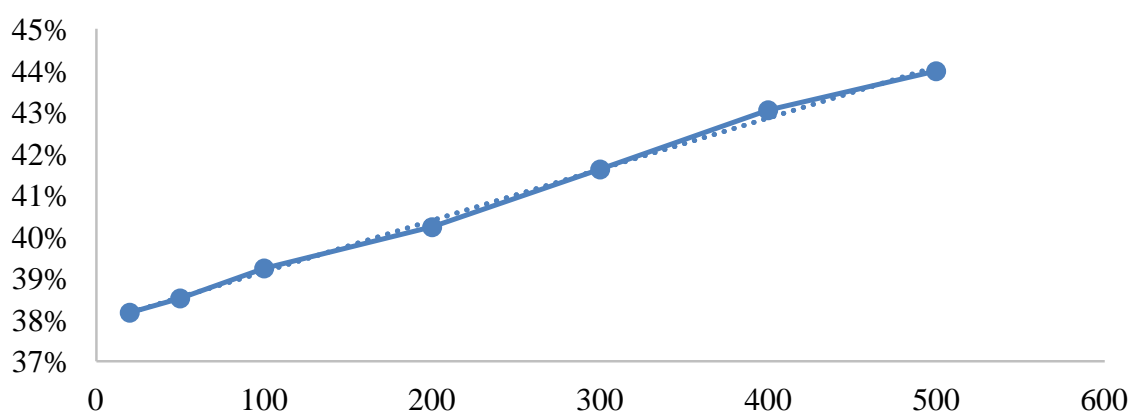

Fig.4: \% of Scavenging activity versus concentration of essential oil.

The remarkable scavenging activities of the essential oil can be attributed to the high flavonoid content in comparison to the phenolic content. Flavonoids are polyphenolic compounds which can be categorized into various groups such as flavonols, flavones, flavanones, isoflavones, catechins, anthocyanidins and chalcones (Subedi et al., 2014). Hence, it can act asscavengers of various oxidizing species and also act as quenchers of singlet oxygen of different chemical structurally.

This is the first ever study which reports the in vitro photo-protective ability of EE (Table 3). The in vitro photoprotective ability determined by the sun protection factor (SPF) was $3.555 \pm 0.025$. This result revealed that the essential oil contains natural compounds which is able to provide UV blockage at least at 50\% (Iman et al., 2015). This natural compounds can be attributed to the present of flavonols such as quercetin, it is believe able to prevent UV radiation-induced damage to plants by increasing quercetin biosynthesis after exposure to the UV rays (Saewan and Jimtaisong, 2013). Besides, the UV energy absorbed could be dissipated as heat, light or through decomposition of flavonols (Saewan and Jimtaisong, 2013). As such, incorporating the $E E$ essential oil into any sunscreen product could suggest an alternative way to replace the synthetic compound. 


\section{CONCLUSION}

This study has successfully reported the phytochemical screening and photo-protective potential of the essential oil from $E E$. Results from this research revealed that the $E E$ essential oil is enriched with secondary metabolites, good anti-oxidant activity and sun protection potential. This study further suggests that the essential oil from $E E$ could be potentially used as a new source of natural anti-oxidant and ingredient that can be incorporated into the sunscreen cosmetic products.

\section{ACKNOWLEDGEMENT}

We are grateful to the laboratory staff of the Royal College of Medicine Perak of University Kuala Lumpur for their invaluable assistance. A heartfelt thanks and appreciation is also due to late Prof Dr Mohd Syafiq bin Abdullah who still remains as a source of strength and inspiration to this researcher.

\section{Financial support and sponsorship: Nil.}

Conflict of Interests: There are no conflicts of interest.

\section{REFERENCES}

Abdelwahab SI, Zaman FQ, Mario A, Yaacob M, Ahmed Abdelmageed AH, Khamis S. Chemical composition, antioxidant and antibacterial properties of the essential oils of Etlingera elatior and Cinnamomum pubescens Kochummen.Journal of the Science of Food and Agriculture, 2010; 90: 2682-2688.

Çetinkaya H, Kulak M, Agriculture F, Arts F. Relationship between total phenolic, total flavonoid and oleuropein in different aged olive (Olea europaea $l$.) Cultivar leaves.Afr J Tradit Complement Altern Med, 2016; 13: 81-85.

Costa SCC, Detoni CB, Branco CRC, Botura MB, Branco A. The health benefits of natural skin UVA photoprotective compounds found in botanical sources.Revista Brasileira de Farmacognosia, 2015; 24: 413-418.

Chan E, Chiang W, Yan LY. Composition and antibacterial activity of essential oils from leaves of Etlingera species (Zingiberaceae). International Journal for the Advancement of Science and Arts, 2010; 2:112.

Choon SY, Ding P. Growth stages of Torch Ginger (Etlingera elatior) Plant. Sains Malaysiana, 2016; 45: 507-515.

Ghasemzadeh A, Jaafar HZE, Rahmat A, Ashkani S. Secondary metabolites constituents and antioxidant, anticancer and antibacterial activities of Etlingera elatior (Jack) R.M.Smith. grown in different locations of Malaysia. Complementary and Alternative Medicine, 2015; $15,335-338$.

Jaafar FM, Osman CP, Ismail NH, Awang K. Analysis of essential oils of leaves, stems, flowers and rhizomes of Etlingera elatior (Jack) R.M.Smith. The Malaysian Journal of Analytical Sciences, 2007; 11: 267-273.

Iman S, Azhar I, Mohmood ZA. In-vitro evaluation of sun protection factor of a cream formulation prepared from extracts of Musa accuminata (L.), Psidium gujava (L.) and Pyrus communis (L.) Asian Journal of Pharmaceutical and Clinical Research, 2015; 8: 234-237.

Kaur CD, Saraf S. Photochemoprotective activity of alcoholic extract of. Camellia sinensis. International Journal of Pharmacology, 2011; 7: 400- 404.
Khalid SA, Azman AN. Identification of mosquito repellent in Etlingera elatior (torch ginger).Journal of Engineering and Applied Sciences. 2016; 11: 6182-6185.

Lachumy SJT, Sasidharan S, Sumathy V, Zuraini Z. (2010). Pharmacological activity, phytochemical analysis and toxicity of methanol extract of Etlingera elatior (torch ginger) flowers. Asian Pacific Journal of Tropical Medicine, 2010; 3: 769-774.

Maimulyanti A, Prihadi AR. Chemical composition , phytochemical and antioxidant activity from extract of Etlingera elatior flower from Indonesia. Journal of Pharmacognosy and Phytochemistry, 2015; 3: 233-238.

Malsawmtluangi C, Nath DK, Jamatia I, Lianhimgthangi, Zarzoliana E, Pachuau L. Determination of Sun Protection Factor (SPF) number of some aqueous herbal extracts. Journal of Applied Pharmaceutical Science, 2013; 2: 150-151.

Mohamed AA, Ali SI, El-Baz FK. Antioxidant and antibacterial activities of crude extracts and essential oils of Syzygium cuminileaves. PLoS ONE, 2013; 8: 1-7.

Napagoda MT, Malkanthi BMAS, Abayawardana SAK, Qader MM, Jayasinghe L. Photoprotective potential in some medicinal plants used to treat skin diseases in Sri Lanka. BMC Complementary and Alternative Medicine, 2016; 16: 1-6.

Nurain A, Noriham A, Zainon MN, Wan Saidatul WSK, Khairusy SZ. Comparative study of aqueous and ethanolic aromatic Malaysian herbs extracts using four antioxidant activity assays. International Journal of Agricultural Research, 2013; 8: 55-66.

Prashant TB, Kumar MK, Gurpreet Kaur HK. Phytochemical screening and extraction - A review. Internationale Pharmaceutica Sciencia, 2010; 1: 98-106.

Rojas J, Londono C, Ciro Y. The health benefits of natural skin UVA photoprotective compounds found in botanical sources. International Journal of Pharmacy and Pharmaceutical Sciences, 2016; 8: 13-23.

Saewam N, Jimtaisong A. Photoprotection of natural flavonoids. Journal of Applied Pharmaceutical Science, 2013; 3: 129-141.

Seow LJ, Morazuki NA, Dash GK. A comparative study on the antioxidant activity of methanol extracts of carica papaya fruits prepared by hot and cold maceration techniques. Journal of Biological and Scientific Opinion, 2016; 4: 71-74.

Siddique AB, Mizanur Rahman SM, Hossain MA. Chemical composition of essential oil by different extraction methods and fatty acid analysis of the leaves of Stevia rebaudiana Bertoni. Arabian Journal of Chemistry, 2012; 1-5.

Silva RV, Costa SCC, Branco CRC, Bronco A. In vitro photoprotective activity of the Spondias purpurea L. peel crude extract and its incorporation in a pharmaceutical formulation. Industrial Crops and Products, 2016; 83: 509-514.

Subedi L, Timalsena S, Duwadi P, Thapa R, Paudel A, Parajuli K. Antioxidant activity and phenol and flavonoid contents of eight medicinal plants from Western Nepal. Journal of Traditional Chinese Medicine, 2014; 34: 584-590.

How to cite this article:

Khor PY, Mohamed FSN, Ramli I, Nor AF, Razali SK, Zainuddin JA, Jaafar NS. Phytochemical, Antioxidant and Photo-Protective Activity Study of BungaKantan (Etlingera elatior) Essential Oil. J App Pharm Sci, 2017; 7 (08): 209-213. 